\title{
Efficacy of Ethanol Ablation for Benign Thyroid Cysts and Predominantly Cystic Nodules: A Systematic Review and Meta-Analysis
}

\author{
Cheng-Chun Yang, Yung Hsu, Jyun-Yan Liou \\ Department of Medical Imaging, Chi Mei Medical Center, Tainan, Taiwan
}

Background: Ultrasound-guided minimally invasive procedures are widely used to treat thyroid diseases. The objective of this study was to assess the efficacy and safety of ethanol ablation (EA) in comparison with other non-surgical options in the treatment of benign thyroid cystic nodules.

Methods: We conducted a systematic search of studies on EA for thyroid cystic nodules, mainly in the Ovid-MEDLINE and Embase, Web of Science, and Cochrane databases. The standardized mean difference (SMD) of the volume reduction ratio (VRR) after EA versus other non-surgical treatments comprised the primary outcome, whereas the odds ratio (OR) of therapeutic success rates between the two groups comprised the secondary outcome.

Results: The meta-analysis included 19 studies (four randomized controlled trials and 15 non-randomized studies) with 1,514 participants. The cumulative VRR of EA was $83.908 \%$ (95\% confidence interval [CI], $79.358 \%$ to $88.457 \%$ ). EA had a significantly higher pooled VRR (SMD, $0.381 ; 95 \% \mathrm{CI}, 0.028$ to $0.734 ; P=0.030$ ), but not a significantly higher pooled therapeutic success rate (OR, $0.867 ; 95 \% \mathrm{CI}, 0.132$ to $5.689 ; P=0.880$ ), than other forms of non-surgical management including radiofrequency ablation (RFA), polidocanol sclerotherapy, and simple aspiration with or without saline flush. However, the VRR and therapeutic success rate were not significantly different between EA and RFA. Major complications were recorded only in six patients ( $0.53 \%)$ with self-limiting dysphonia.

Conclusion: The role of EA as the first-line treatment for benign thyroid cysts and predominantly cystic nodules is supported by its high effectiveness and good safety profile compared to other currently available non-surgical options.

Keywords: Ethanol; Ablation techniques; Sclerotherapy; Thyroid nodule; Cyst; Meta-analysis

\section{INTRODUCTION}

Thyroid nodules are very common incidental findings, detected in up to $67 \%$ of the general population by ultrasonography, and $15 \%$ to $25 \%$ of thyroid nodules are cystic [1,2]. Around $5 \%$ of patients with thyroid nodules may experience compressive symptoms or cosmetic concerns, and treatment may be required in these cases [3]. Simple aspiration is generally the initial management for the purpose of diagnosis and cyst volume reduction. However, the recurrence rate has been reported to be high
Received: 1 September 2020, Revised: 10 November 2020, Accepted: 10 December 2020

Corresponding author: Jyun-Yan Liou

Division of Interventional Radiology, Department of Medical Imaging, Chi Mei Medical Center, No. 901, Zhonghua Rd., Yongkang Dist., Tainan 710, Taiwan Tel: +886-6-281-2811, Fax: +886-6-622-2547, E-mail: wesbox@gmail.com
Copyright $\odot 2021$ Korean Endocrine Society

This is an Open Access article distributed under the terms of the Creative Commons Attribution Non-Commercial License (https://creativecommons.org/ licenses/by-nc/4.0/) which permits unrestricted non-commercial use, distribution, and reproduction in any medium, provided the original work is properly cited. 
( $40 \%$ to $59 \%$ ), depending on the number of aspirations and extent of fluid evacuation $[4,5]$.

Ultrasound-guided percutaneous ethanol ablation (EA) is an effective and safe alternative to surgery in cases of recurrence. The reported volume reduction ratio (VRR) after EA in thyroid cysts (cystic portion $>90 \%$ ) and predominantly cystic thyroid nodules (PCTNs; typically defined as having a cystic portion of $50 \%$ to $90 \%$ ) ranges from $80 \%$ to $100 \%$ and from $65 \%$ to $85.4 \%$, respectively [6-13]. In contrast, the efficacy of EA for treating benign solid thyroid nodules remains controversial, and EA is not recommended in current guidelines for solid nodules [14]. The therapeutic mechanism of EA is a combination of coagulative and ischemic necrosis. The former is caused by direct ethanol toxicity leading to cell dehydration and protein denaturation, while the latter is induced by the entrance of ethanol into the local circulation, resulting in endothelial injury, subsequent thrombosis, and ischemia. Coagulative necrosis is considered to be the predominant effect on cystic lesions [15-17]. Although EA has been proposed as the first-line treatment for relapsing symptomatic cystic thyroid nodules in most guidelines [14,1822], their recommendations point out a wide range of strengths based on previous reports with heterogeneous quality of evidence. The 2018 consensus statement on EA released by Korean Society of Thyroid Radiology accentuated the role of EA in treating benign thyroid cysts and PCTNs by summarizing more recent high-quality evidence, and further expanded its clinical scope for the management of hyperfunctioning thyroid nodules and local recurrent thyroid carcinoma in selected cases [22].

In recent years, thermal ablation has emerged as a popular non-surgical treatment for benign solid thyroid nodules and recurrent thyroid cancers [21]. In particular, radiofrequency ablation (RFA) has been shown to be effective for treating cystic thyroid nodules $[8,10,13,23-26]$. The objective of this study was to conduct a comprehensive meta-analysis to compare the efficacy and safety of EA with that of other non-surgical options, including RFA, for the treatment of benign thyroid cystic nodules.

\section{METHODS}

\section{Literature search}

This meta-analysis adhered to the standard guidelines of Preferred Reporting Items for Systematic Reviews and Meta-Analyses (PRISMA). Two reviewers (C.C.Y. and Y.H.) independently conducted a systematic search of the databases, including Ovid-MEDLINE and Embase, Web of Science, Cochrane Sys- tematic Reviews, Cochrane Collaboration Central Register of Controlled Clinical Trials, ClinicalTrials.gov and Scopus. Additionally, major Korean medical databases including Korean Medical Article Database, KoreaMed.org, and KoreaMed Synapse were also searched, since most recent studies of EA are from Korea. The search strategy for Ovid-MEDLINE and Embase is presented in Supplemental Table S1. The search was updated to extend through October 2020.

\section{Inclusion criteria}

To conform to the population, intervention, comparison, and outcomes (PICO) strategy, our inclusion criteria were set as follows: (1) population: patients with thyroid cysts or PCTNs, for which benignity should be confirmed by fine-needle aspiration; (2) intervention and comparison: two-arm parallel studies comparing EA with other types of non-surgical management, and single-arm studies or case series involving EA with more than 10 participants; and (3) outcome: results reported in sufficient detail to evaluate the VRR (primary outcome, defined as: [final volume-baseline volume]/baseline volume), and therapeutic success rate (secondary outcome, defined as a volume reduction from baseline of more than $50 \%$ ).

\section{Exclusion criteria}

Studies were excluded if any of the following criteria were met: (1) conference abstracts, letters, case series or case reports with fewer than 10 participants; (2) studies not written in English or for which the full text was not available; (3) studies with, or with suspicion of, overlapping populations; (4) studies that either had an arbitrary definition of benign thyroid cystic nodules, or did not enroll those with a cystic portion $\geq 50 \%$ of the nodule volume; and (5) studies that combined EA and other therapies as a whole.

\section{Data extraction}

One researcher (C.C.Y.) extracted the data from selected studies, while the other researcher (Y.H.) verified the accuracy. The following data was extracted with a standardized form: (1) mean VRR; (2) therapeutic success rate; (3) the types of nodules and their mean baseline volume; (4) patient demographics, including mean age and sex; (5) technical details, including the volume and concentration of injected ethanol, the retention and aspiration of injected ethanol, and number of treatment sessions; (6) timing of ultrasound follow-up; and (7) minor and major complications, categorized according to the new Society of Interventional Radiology classification [27]. Minor complications 
were defined as adverse events without requiring therapy, which were referred to as side effects in this study; major complications were defined as adverse events necessitating substantial therapy, escalation of care, hospitalization, life-threatening morbidity, or even mortality (Table 1).

\section{Quality assessment}

Two researchers independently assessed the quality of each included study with scoring systems corresponding to the research methodology. The Cochrane Risk-of-Bias tool 2.0 (RoB 2.0) contains five domains for the identification of potential source of bias in randomized controlled trials (RCTs): the randomization process, deviations from intended interventions, missing outcome data, the measurement of the outcomes, and selection of the reported results [28]. The Risk of Bias Assessment Tool for Nonrandomized Studies (RoBANS) evaluates the risk of bias in non-randomized studies (NRS) based on six domains: selection of participants, confounding variables, measurement of exposure, blinding of outcome assessment, incomplete outcome data, and selective outcome reporting [29]. Between-reviewer discrepancies were resolved through discussions under the supervision of the corresponding author.

\section{Statistical synthesis and analysis}

The standardized mean difference (SMD) of the VRR between EA and the control group comprised the primary outcome. A positive SMD indicates that EA was the favorable non-surgical treatment option. The effect size was analyzed in terms of the odds ratio (OR) for identifying the therapeutic success rate of EA. An OR $>1$ indicates that the EA group had a higher success rate than the control group. The inverse variance method and Mantel-Haenszel method were used to estimate the effect size of continuous and dichotomous variables, respectively. Additionally, the generic inverse variance method was employed to pool individual mean VRRs. A random-effects model was used to calculate each overall effect size. Sensitivity analyses, funnel plots and the Egger test were used to examine publication bias. A quantitative synthesis was done using the Cochrane Collaboration's software RevMan 5.4, whereas the Egger test and sensitivity analyses were carried out using Comprehensive MetaAnalysis software version 3 (Biostat, Englewood, NJ, USA). Attempts were made to contact authors for missing data, and the remaining instances of missing data were dealt with reasonable imputation according to the Cochrane Handbook version 6. Between-trial heterogeneity was determined by the inconsistency index $\left(I^{2}\right)$, with values of $25 \%, 50 \%$, and $75 \%$ representing low, moderate, and high degrees of inconsistency or statistical heterogeneity, respectively [30].

\section{RESULTS}

\section{Literature search and characteristics of the included studies}

A total of 1,772 non-duplicate potentially eligible studies were identified through screening the titles and abstracts, from which 46 articles were retrieved for full text review. The final metaanalysis included 19 studies, consisting of eight two-arm parallel studies (four RCTs [10,11,13,31], two prospective cohort studies [6,32], and two retrospective cohort studies [8,9]), which compared EA with other types of non-surgical management, and 11 single-arm studies (Fig. 1) [7,12,33-41]. Of note, Verde et al. [32] conducted a preliminary RCT followed by a prospective cohort, which was integrated into a larger cohort by pooling the VRRs at 1 month. The characteristics of the included studies are summarized in detail in Table 1.

\section{Characteristics of the ablation techniques}

Almost all EA procedures described in the included studies involved subtotal or complete aspiration of the fluid content of cystic nodules prior to ethanol instillation. The injected ethanol was either evacuated (aspiration technique) or retained (retention technique) after the procedure in seven $[8-11,13,32,35]$ and three $[31,40,41]$ studies, respectively. Notably, among studies that enrolled PCTNs, none of them mentioned injection of ethanol into the solid component in addition to filling of the cystic cavity. The procedure was well-tolerated by most participants, with no requirement for local anesthesia. Four trials evaluated the VRR after performing a single session of EA [10,13,32,35], whereas in the other studies, the VRR was assessed after some or all of the participants underwent multiple treatment sessions. The details of the EA techniques in the included studies are also presented in Table 1.

\section{Assessment of study quality}

The results of the quality assessment of the four included RCTs according to the RoB 2.0 tool are presented in Fig. 2A, Supplemental Fig. S1A. All four RCTs had a low risk of bias in the domains of deviations from intended interventions, missing outcome data, measurement of outcomes, and selection of the reported results. Three of the four studies were considered to have some concerns in the randomization process because the authors did not state allocation concealment [10,13,31], and one of them 


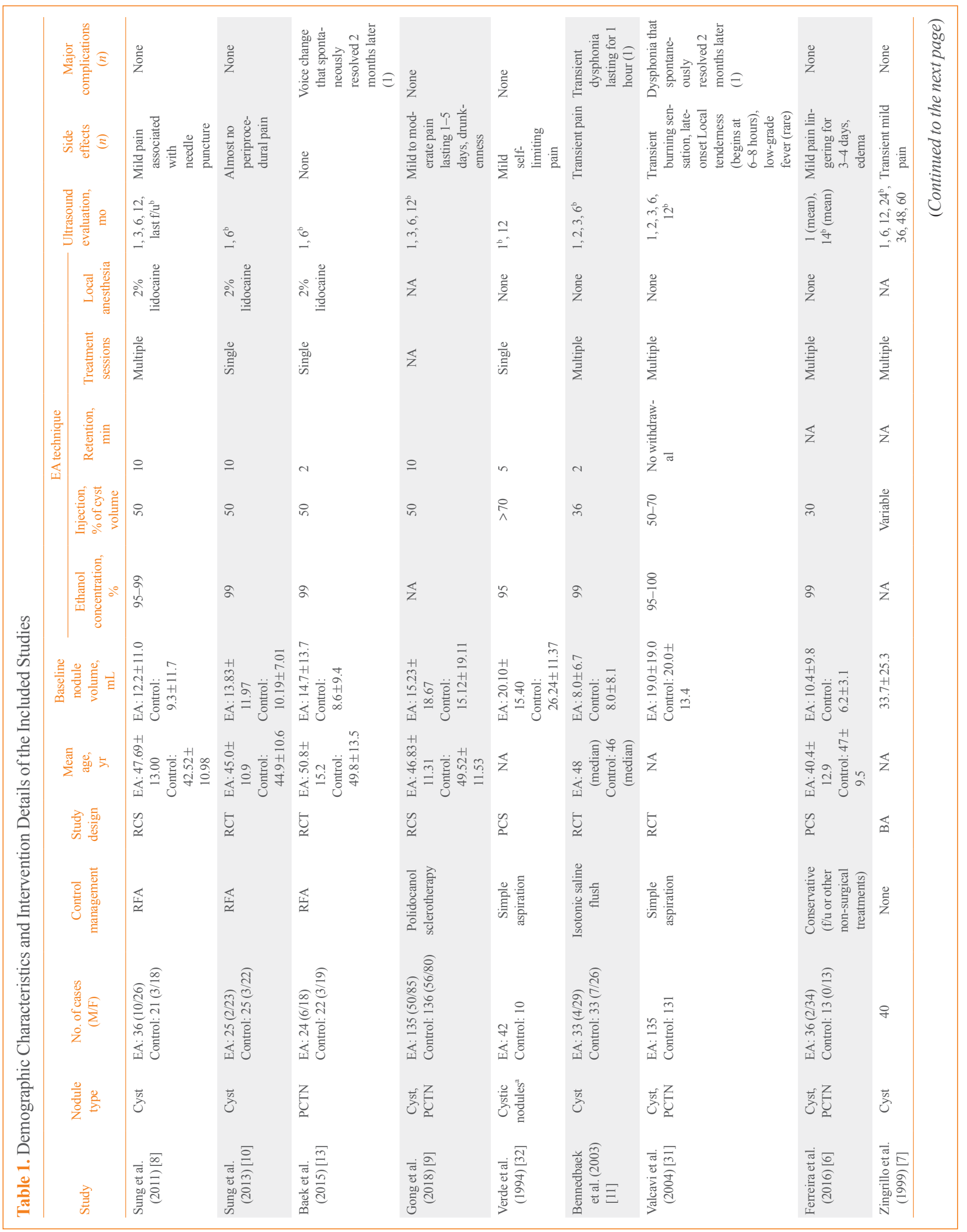




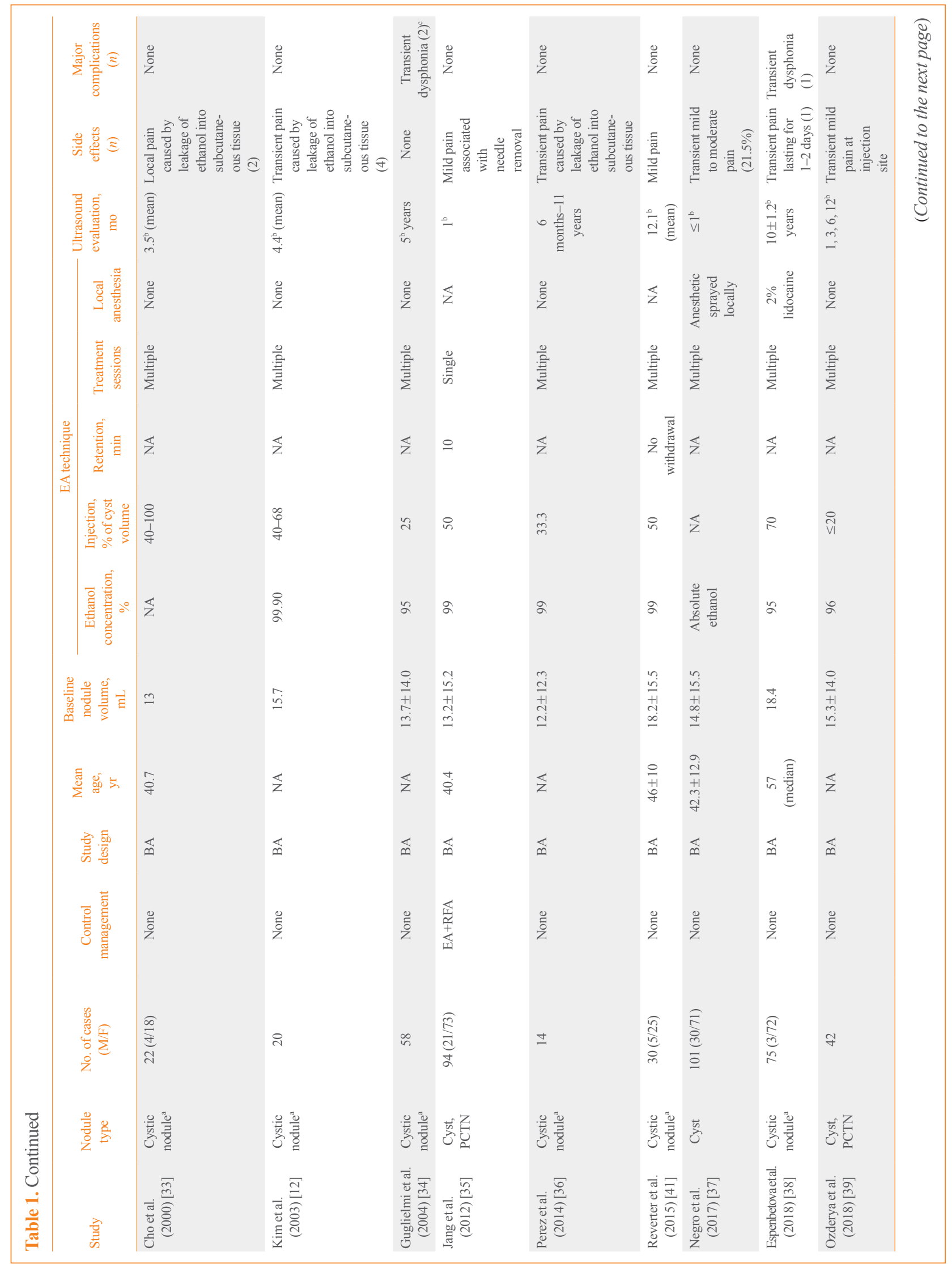




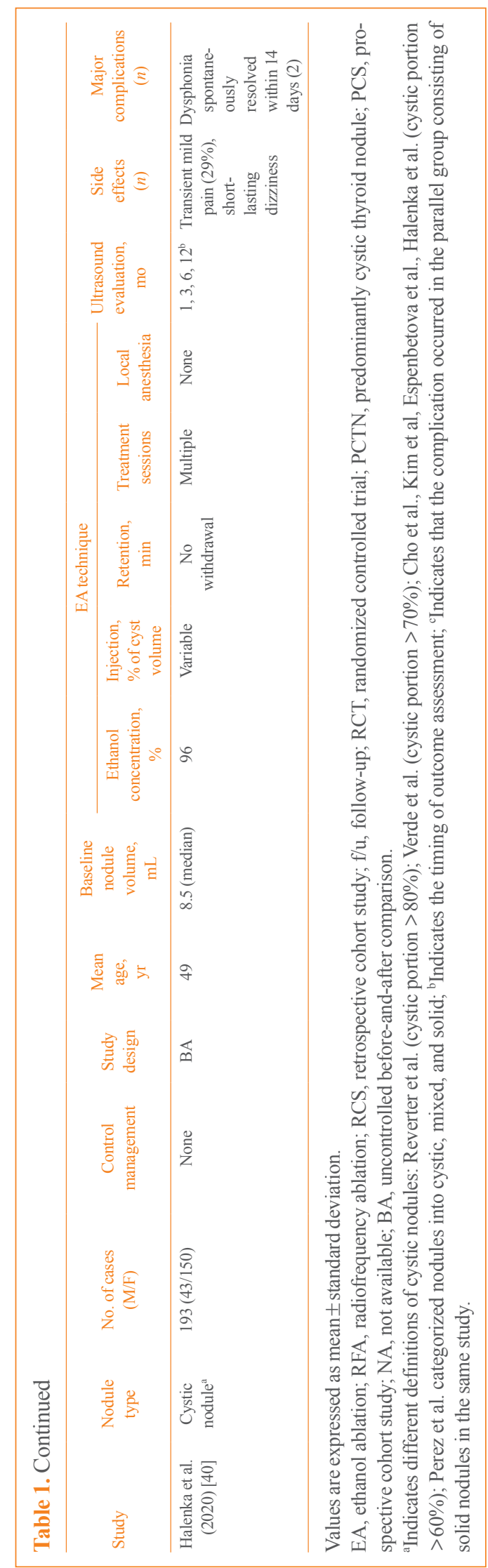

had a significant baseline imbalance in nodule volume and diameter [13]. The results of the methodological assessment of the 15 included NRSs according to the RoBANS are shown in Fig. 2B, Supplemental Fig. S1B. All the studies had a low risk of bias in the domain of selective outcome reporting, whereas most of them had an unclear risk of bias in the domain of blinding of outcome assessments. Six studies had a low risk of bias in the patient selection domain [6-9,35,38], while the others were given an unclear or high risk of bias due to an uncertain process of patient recruitment $[12,33,39,41]$ and retrospective data collection $[34,36,37,40]$ or selection of the intervention and control groups from different populations [32], respectively. One study had high risk of bias in the incomplete data domain due to a large number of dropout cases in long-term follow-up [7]. Additionally, one study had high and unclear risks of bias in the domains of confounding variables and measurement of exposure, respectively, because some of the patients in the control group received an additional suppressive dose of levothyroxine and the potential confounding effect on VRR was not investigated, and because it was not clearly described how exposure data were obtained [6].

\section{Quantitative synthesis (meta-analysis) Cumulative mean VRR of EA}

The cumulative mean VRR of all the included 19 studies was $83.908 \%$ (95\% confidence interval [CI], $79.358 \%$ to $88.457 \%$ ), irrespective of the timing of ultrasound evaluation and number of treatment sessions. The pooled VRRs at 1, 6, and 12 months were $70.012 \%$ (95\% CI, $62.620 \%$ to $77.404 \%$ ), $90.754 \%$ (95\% CI, $84.015 \%$ to $97.494 \%$ ), and $84.966 \%$ ( $95 \%$ CI, $79.080 \%$ to $90.852 \%)$, respectively.

\section{SMD of the VRR between EA and other types of non-surgical management}

Overall, eight studies compared the VRR between EA and other non-surgical options $[6,8-11,13,31,32]$. The pooled SMD of EA versus other types of non-surgical management concerning VRR was 0.381 ( $95 \% \mathrm{CI}, 0.028$ to $\left.0.734 ; P=0.030 ; I^{2}=79 \%\right)$ (Fig. 3A). Subgroup analysis revealed no significant difference between VRR in the EA group and the RFA group (SMD, $0.170 ; 95 \% \mathrm{CI},-0.367$ to $0.708 ; P=0.530 ; I^{2}=61 \%$ ), whereas the VRR of EA was significantly higher than that of simple aspiration with or without isotonic saline flush (SMD, 0.716; 95\% CI, 0.292 to $1.140 ; P<0.001 ; I^{2}=57 \%$ ) (Fig. 3A). EA had a similar VRR to that of polidocanol sclerotherapy (SMD, $-0.171 ; 95 \% \mathrm{CI},-0.410$ to $0.068 ; P=0.160$ ) (Fig. $3 \mathrm{~A}$ ). In the 


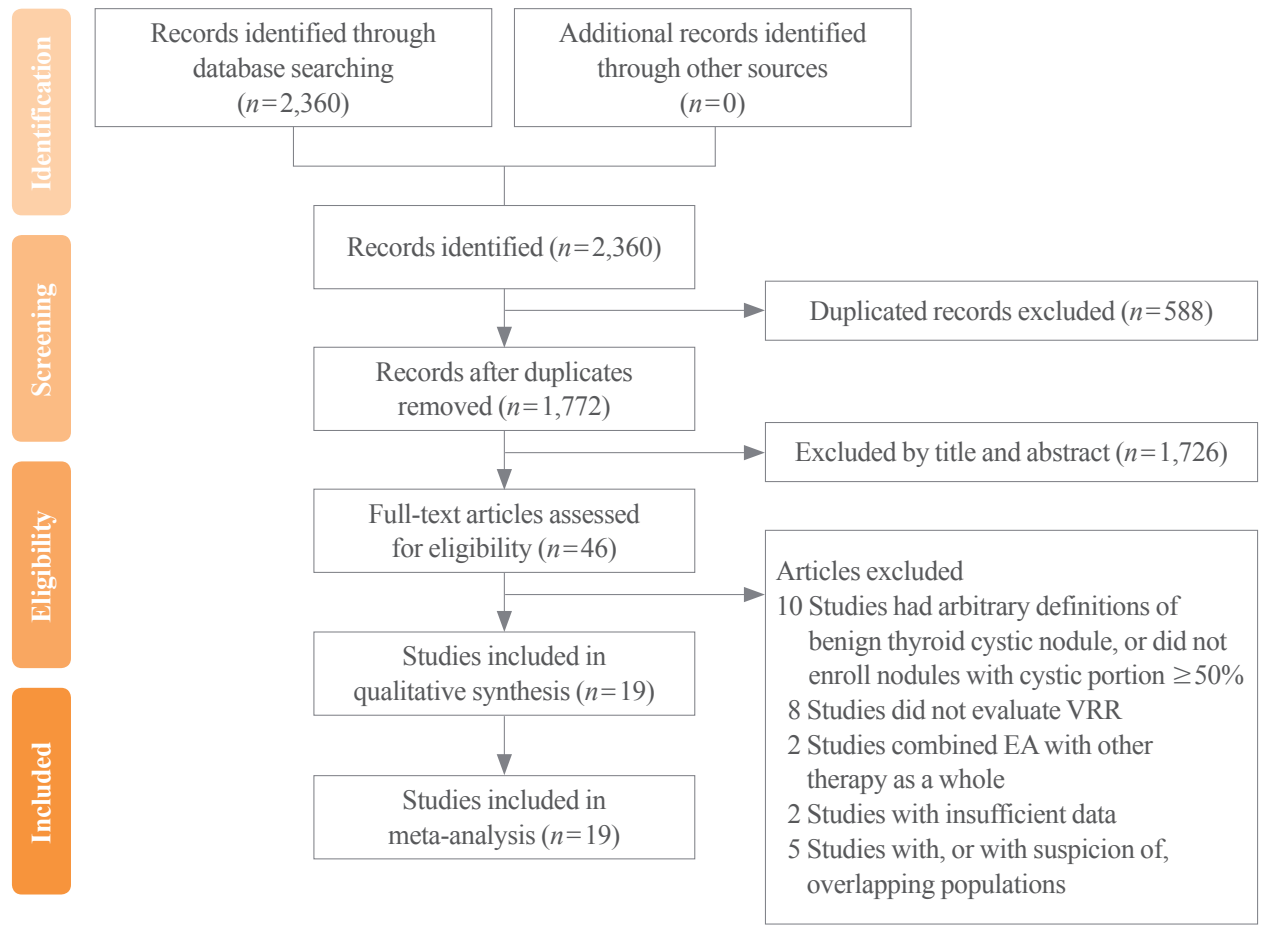

Fig. 1. Flow diagram summarizing the literature review process according to the Preferred Reporting Items for Systemic Reviews and MetaAnalysis (PRISMA) guideline. VRR, volume reduction ratio; EA, ethanol ablation.

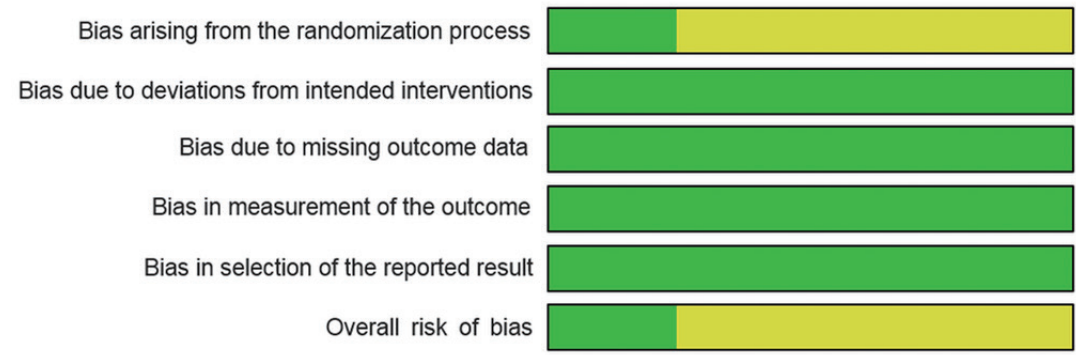

\begin{tabular}{|ll|}
\hline Low risk of bias $\quad \square$ Some concerns $\quad \square$ High risk of bias \\
\hline
\end{tabular}
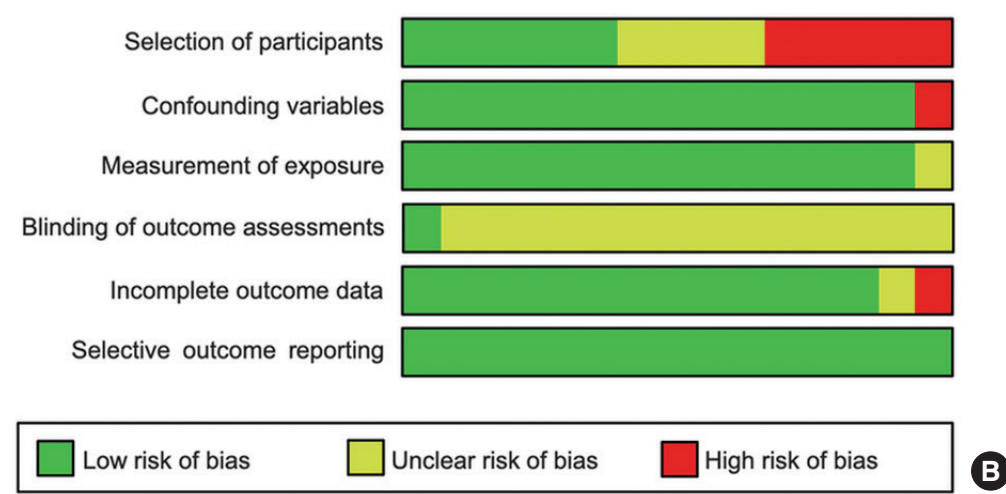

Fig. 2. Summary of quality assessment of the included randomized controlled trials according to Risk-of-Bias tool 2.0 (RoB 2.0) (A), and non-randomized studies according to Risk of Bias Assessment Tool for Nonrandomized Studies (RoBANS) (B). 


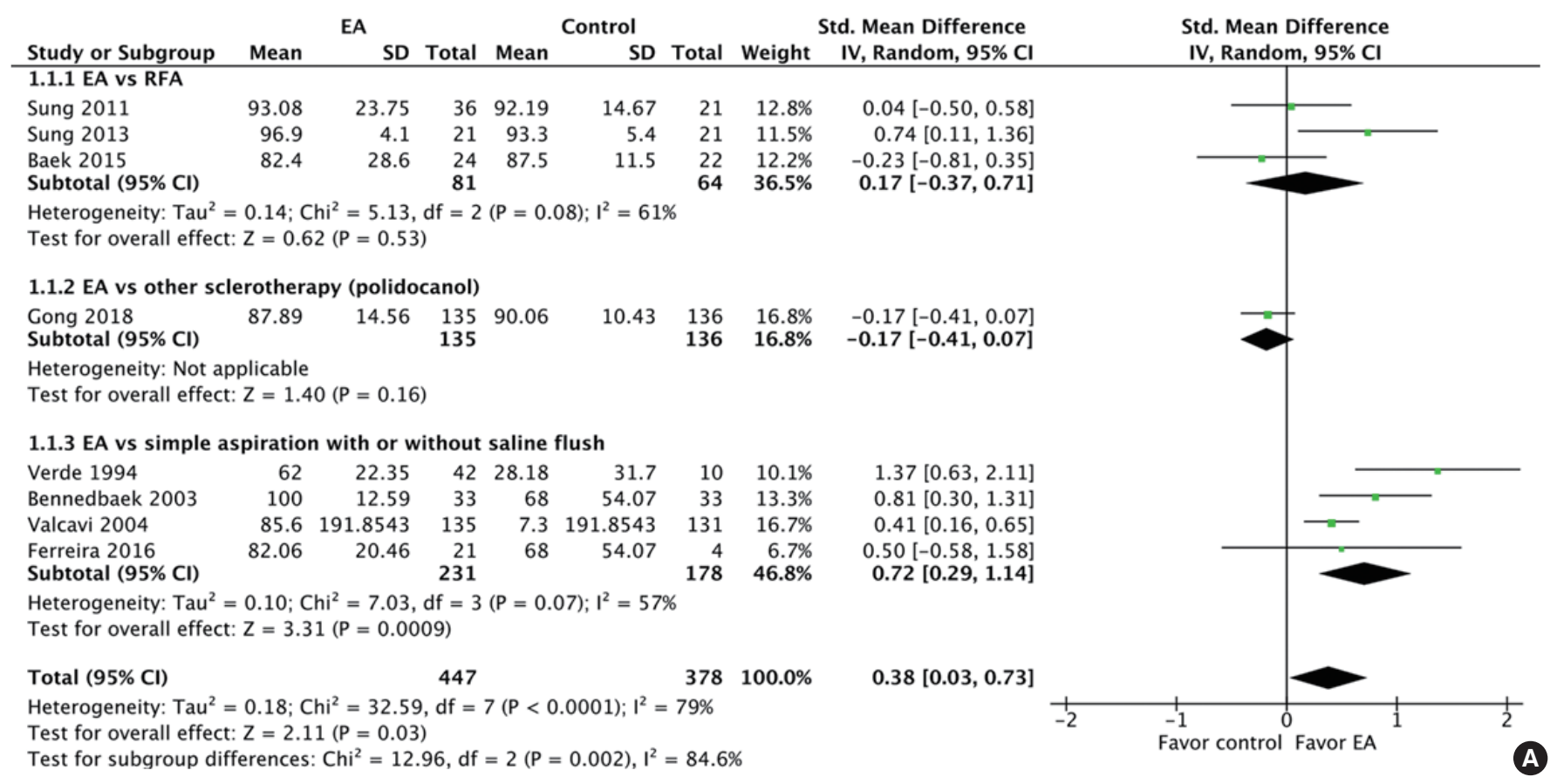

\begin{tabular}{|c|c|c|c|c|c|c|c|}
\hline \multirow[b]{2}{*}{ Study or Subgroup } & \multicolumn{3}{|c|}{ EA } & \multicolumn{3}{|c|}{ Control } & \multirow{2}{*}{ Weight } \\
\hline & Mean & SD & Total & Mean & SD & Total & \\
\hline \multicolumn{8}{|l|}{2.1 .1 cyst } \\
\hline Sung 2011 & 93.08 & 23.75 & 36 & 92.19 & 14.67 & 21 & $15.5 \%$ \\
\hline Sung 2013 & 96.9 & 4.1 & 21 & 93.3 & 5.4 & 21 & $13.7 \%$ \\
\hline Gong 2018 & 94.43 & 8.81 & 70 & 95.55 & 7.9 & 75 & $20.2 \%$ \\
\hline $\begin{array}{l}\text { Bennedbaek } 2003 \\
\text { Subtotal }(95 \% \mathrm{Cl})\end{array}$ & 100 & 12.59 & $\begin{array}{r}33 \\
160\end{array}$ & 68 & 54.07 & $\begin{array}{r}33 \\
150\end{array}$ & $\begin{array}{l}16.3 \% \\
65.7 \%\end{array}$ \\
\hline \multicolumn{8}{|c|}{$\begin{array}{l}\text { Heterogeneity: } \mathrm{Tau}^{2}=0.19 ; \mathrm{Chi}^{2}=12.73, \mathrm{df}=3(\mathrm{P}=0.005) ; \mathrm{I}^{2}=76 \% \\
\text { Test for overall effect: } \mathrm{Z}=1.31(\mathrm{P}=0.19)\end{array}$} \\
\hline \multicolumn{8}{|l|}{ 2.1.2 PCTN } \\
\hline Baek 2015 & 82.4 & 28.6 & 24 & 87.5 & 11.5 & 22 & $14.6 \%$ \\
\hline $\begin{array}{l}\text { Gong } 2018 \\
\text { Subtotal }(95 \% \mathrm{Cl})\end{array}$ & 80.84 & 16.22 & $\begin{array}{l}65 \\
89\end{array}$ & 83.3 & 9.15 & $\begin{array}{l}61 \\
83\end{array}$ & $\begin{array}{l}19.7 \% \\
34.3 \%\end{array}$ \\
\hline \multicolumn{8}{|c|}{$\begin{array}{l}\text { Heterogeneity: } \mathrm{Tau}^{2}=0.00 ; \mathrm{Chi}^{2}=0.01, \mathrm{df}=1(P=0.90) ; \mathrm{I}^{2}=0 \% \\
\text { Test for overall effect: } Z=1.28(P=0.20)\end{array}$} \\
\hline Total $(95 \% \mathrm{Cl})$ & & & 249 & & & 233 & $100.0 \%$ \\
\hline \multicolumn{8}{|c|}{$\begin{array}{l}\text { Heterogeneity: } \mathrm{Tau}^{2}=0.13 ; \mathrm{Chi}^{2}=17.07, \mathrm{df}=5(\mathrm{P}=0.004) ; \mathrm{I}^{2}=71 \% \\
\text { Test for overall effect: } \mathrm{Z}=0.80(\mathrm{P}=0.43) \\
\text { Test for subgroup differences: } \mathrm{Chi}^{2}=3.16, \mathrm{df}=1(\mathrm{P}=0.08), \mathrm{I}^{2}=68.4 \%\end{array}$} \\
\hline
\end{tabular}

Std. Mean Difference V, Random, 95\% Cl

$0.04[-0.50,0.58]$

$0.74[0.11,1.36]$

$-0.13[-0.46,0.19]$

$0.81[0.30,1.31]$

$0.33[-0.17,0.83]$

Std. Mean Difference IV, Random, $95 \% \mathrm{CI}$

Fig. 3. Forest plots summarizing the efficacy of ethanol ablation (EA) in treating cystic thyroid nodules measured by the volume reduction ratio as compared with other types of non-surgical management, overall effects, and subgroup analysis according to different comparators (A) and cysts versus predominantly cystic thyroid nodules (PCTNs) (B). SD, standard deviation; IV, inverse variance method; CI, confidence interval; RFA, radiofrequency ablation.

subgroup analysis of cysts versus PCTNs, one study [8] compared the two types of nodules separately and was therefore treated as containing two different datasets. Three studies were removed from consideration, including two [6,31] that combined the data of the different types of nodules, and another [32] that enrolled PCTNs with a different definition (cyst content
$>70 \%$ ), because the authors believed that it was not reasonable to combine them into either group. Finally, we included six datasets from five studies for this subgroup analysis. As compared with other types of non-surgical management, the VRR after EA was higher in thyroid cysts (SMD, $0.333 ; 95 \% \mathrm{CI},-0.166$ to $0.832 ; P=0.190 ; I^{2}=76 \%$ ) but not in PCTNs (SMD, -0.195 ; 
Table 2. Subgroup Analysis of Standardized Mean Difference Based on Study Design, Retention and Aspiration Techniques, and Injected Volume of Ethanol, and Number of Treatment Sessions

\begin{tabular}{|c|c|c|c|c|}
\hline Subgroup & Standardized mean difference & $95 \% \mathrm{CI}$ & $P$ value & $I^{2}, \%$ \\
\hline \multicolumn{5}{|l|}{ Study design } \\
\hline $\mathrm{RCT}$ & 0.434 & 0.054 to 0.814 & 0.030 & 63 \\
\hline NRS & 0.364 & -0.292 to 1.021 & 0.280 & 81 \\
\hline \multicolumn{5}{|c|}{ Retention and aspiration of injected ethanol } \\
\hline Aspiration & 0.384 & -0.103 to 0.870 & 0.120 & 83 \\
\hline Retention & 0.407 & 0.164 to 0.650 & 0.001 & NA \\
\hline \multicolumn{5}{|l|}{ Injected volume } \\
\hline$\geq 50 \%$ of cyst volume & 0.300 & -0.095 to 0.696 & 0.140 & 81 \\
\hline$<50 \%$ of cyst volume & 0.751 & 0.295 to 1.207 & 0.001 & 0 \\
\hline \multicolumn{5}{|l|}{ Treatment session } \\
\hline Single & 0.605 & -0.304 to 1.514 & 0.190 & 83 \\
\hline Multiple & 0.428 & 0.149 to 0.707 & 0.003 & 28 \\
\hline
\end{tabular}

95\% CI, -0.495 to $0.104 ; P=0.200 ; I^{2}=0 \%$ ), although neither SMD achieved statistical significance (Fig. 3B). Table 2 presents the results of other subgroup analyses of SMDs based on study design, retention, and aspiration [42], injected ethanol volume, and the number of treatment sessions. Notably, in the subgroups of RCTs and studies that performed multiple treatment sessions, the SMDs of EA were significantly higher than those of the control treatments.

\section{OR of the therapeutic success rate for $E A$ and other types of non-surgical management}

Among the eight included parallel studies, five trials [8-10,13, 32] were available for a quantitative analysis of the therapeutic success rate of EA and other non-surgical options. Of note, the therapeutic success rate was $100 \%$ in one arm of the study by Baek et al. [13], which was resolved by applying a continuity correction of 0.5 to each cell of the $2 \times 2$ table. However, one study was not included in the estimation of the pooled OR by default in the RevMan software because the therapeutic success rate was $100 \%$ in both arms [10], as such trials have a small effect on the pooled OR even when they comprise the large majority of included studies [43]. The pooled OR of the therapeutic success rates for EA as compared with other non-surgical managements was 0.867 (95\% CI, 0.132 to $5.689 ; P=0.880$; $I^{2}=75 \%$ ) (Fig. 4A). A subgroup analysis showed no significant differences in the therapeutic success rate between EA and RFA (OR, 0.485; 95\% CI, 0.071 to 3.328; $P=0.460 ; I^{2}=0 \%$ ) (Fig. $4 \mathrm{~A})$. In the subgroup analysis of cysts versus PCTNs, the thera- peutic success rate of EA was lower than the control types of management (RFA and polidocanol sclerotherapy) in both cysts and PCTNs ([OR, 0.488; 95\% CI, 0.091 to 2.61; $P=0.400$; $I^{2}=0 \%$ ] and [OR, $0.269 ; 95 \% \mathrm{CI}, 0.079$ to $0.921 ; P=0.040$; $\left.I^{2}=0 \%\right]$, respectively) (Fig. $4 \mathrm{~B}$ ).

\section{Side effects and major complications}

The most common side effect was mild to moderate local pain, which was transient and self-limiting in nearly all cases, without the need for analgesics. Drunkenness was reported to affect a small portion of the participants $(10.4 \%)$ in one study [9]. Lowgrade fever was a rare side effect documented by Valcavi and Frasoldati [31], which spontaneously resolved within 2 to 3 days without medication. Dysphonia was the major complication reported in eight patients from six studies [11,13,31, $34,38,40]$, with symptom duration ranging from a few minutes to 2 months. Two of the cases complicated by transient dysphonia reported by Guglielmi et al. [34] occurred in the other parallel group consisting of solid nodules, rather than the cystic nodules. Overall, the incidence of self-limiting dysphonia was $0.53 \%$ (six of the included 1,136 cases) in patients who underwent EA for benign thyroid cysts and PCTNs.

\section{Sensitivity analysis and publication bias}

In the sensitivity analysis (Supplemental Table S2), the quantitative syntheses were repeated after removing one study at a time. Although omitting individual trials did not change the direction of the relationship (favoring EA), the pooled SMD be- 


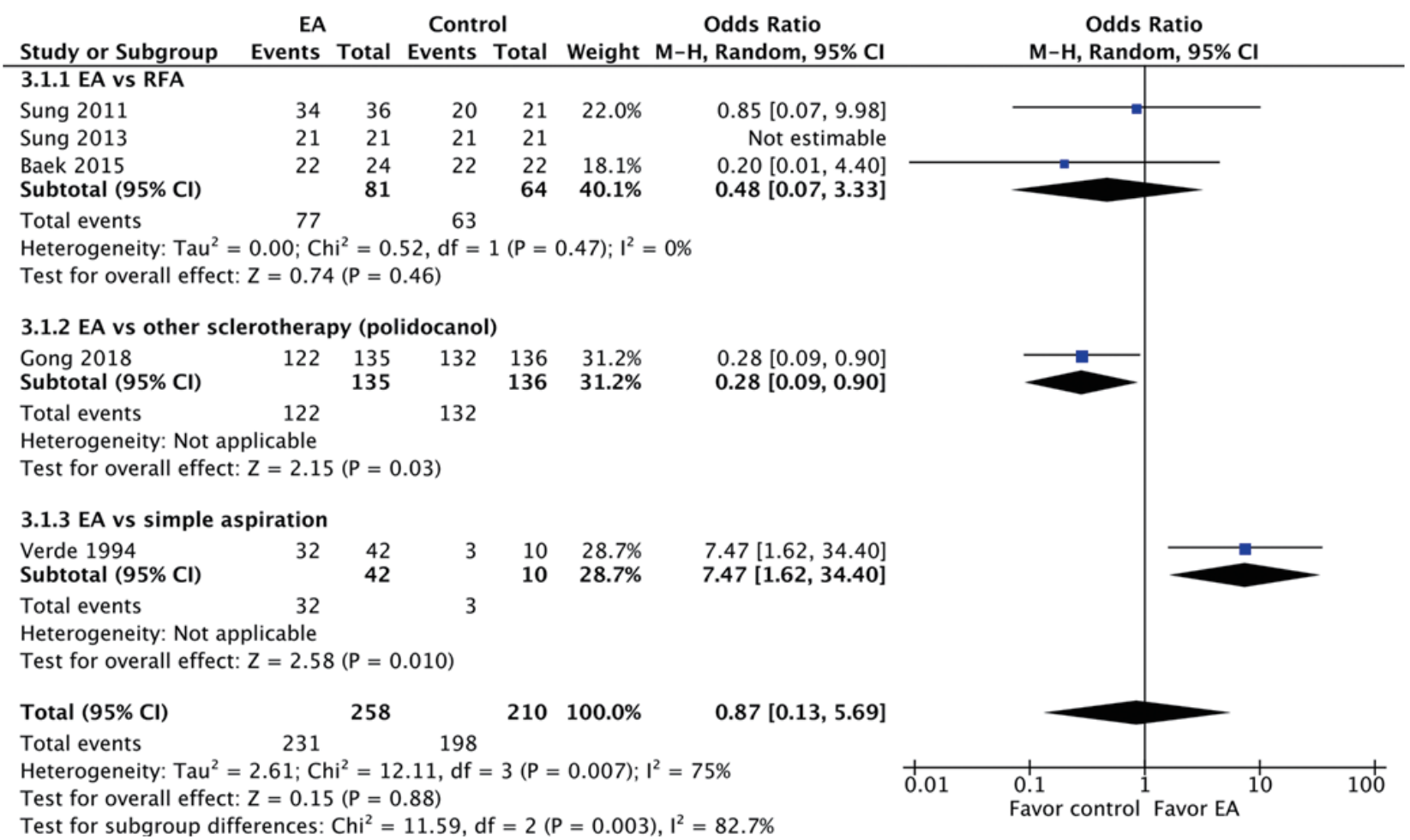

\begin{tabular}{|c|c|c|c|c|c|c|c|c|c|c|}
\hline \multirow{2}{*}{$\begin{array}{l}\text { Study or Subgroup } \\
\text { 4.1.1 cyst }\end{array}$} & \multicolumn{2}{|l|}{ EA } & \multicolumn{2}{|c|}{ Control } & \multirow[t]{2}{*}{ Weight } & \multicolumn{2}{|l|}{ Odds Ratio } & \multicolumn{2}{|c|}{$\begin{array}{c}\text { Odds Ratio } \\
\text { M-H, Random, } 95 \% \mathrm{Cl}\end{array}$} & \\
\hline & & & & & & & & & & \\
\hline Sung 2011 & 34 & 36 & 20 & 21 & $16.2 \%$ & $0.85[0.07,9.98]$ & & & & \\
\hline Sung 2013 & 21 & 21 & 21 & 21 & & Not estimable & & & & \\
\hline $\begin{array}{l}\text { Gong } 2018 \\
\text { Subtotal }(95 \% \mathrm{CI})\end{array}$ & 67 & $\begin{array}{r}70 \\
127\end{array}$ & 74 & $\begin{array}{r}75 \\
117\end{array}$ & $\begin{array}{l}18.8 \% \\
35.0 \%\end{array}$ & $\begin{array}{l}0.30[0.03,2.97] \\
0.49[0.09,2.61]\end{array}$ & & & & \\
\hline \multicolumn{11}{|c|}{$\begin{array}{l}\text { Heterogeneity: } \mathrm{Tau}^{2}=0.00 ; \mathrm{Chi}^{2}=0.37, \mathrm{df}=1(\mathrm{P}=0.55) ; \mathrm{I}^{2}=0 \% \\
\text { Test for overall effect: } \mathrm{Z}=0.84(\mathrm{P}=0.40)\end{array}$} \\
\hline \multicolumn{10}{|l|}{ 4.1.2 PCTN } & \\
\hline Baek 2015 & 22 & 24 & 22 & 22 & $10.3 \%$ & $0.20[0.01,4.40]$ & & & & \\
\hline $\begin{array}{l}\text { Gong } 2018 \\
\text { Subtotal }(95 \% \mathrm{Cl})\end{array}$ & 55 & $\begin{array}{l}65 \\
89\end{array}$ & 58 & $\begin{array}{l}61 \\
83\end{array}$ & $\begin{array}{l}54.7 \% \\
65.0 \%\end{array}$ & $\begin{array}{l}0.28[0.07,1.09] \\
0.27[0.08,0.92]\end{array}$ & & & & \\
\hline \multicolumn{11}{|c|}{$\begin{array}{l}\text { Heterogeneity: } \mathrm{Tau}^{2}=0.00 ; \mathrm{Chi}^{2}=0.04, \mathrm{df}=1(\mathrm{P}=0.84) ; \mathrm{I}^{2}=0 \% \\
\text { Test for overall effect: } \mathrm{Z}=2.09(\mathrm{P}=0.04)\end{array}$} \\
\hline Total $(95 \% \mathrm{CI})$ & & 216 & & 200 & $100.0 \%$ & $0.33[0.12,0.89]$ & & & & \\
\hline Total events & 199 & & 195 & & & & & & & \\
\hline $\begin{array}{l}\text { Heterogeneity: Tau } \\
\text { Test for overall effect } \\
\text { Test for subgroup dif }\end{array}$ & $\begin{array}{l}0.00 ; C h \\
Z=2.18 \\
\text { erences: }\end{array}$ & $\begin{array}{l}\mathrm{i}^{2}=0 . \\
(\mathrm{P}=0 \\
\mathrm{Chi}^{2}=\end{array}$ & $\begin{array}{l}72, \mathrm{df}= \\
0.03) \\
0.31, \mathrm{df}\end{array}$ & $\begin{array}{l}3(P= \\
=1(P\end{array}$ & $\begin{array}{l}0.87) ; 1^{2}= \\
=0.58), 1\end{array}$ & $\begin{array}{l}=0 \% \\
1^{2}=0 \%\end{array}$ & 0.01 & $\begin{array}{ll}0.1 \\
\text { Favor control }\end{array}$ & Favor EA & 100 \\
\hline
\end{tabular}

Fig. 4. Forest plots summarizing the therapeutic success rate of ethanol ablation (EA) as compared with other types of non-surgical management, overall effects, and subgroup analysis according to different comparators (A) and cysts versus predominantly cystic thyroid nodules (PCTNs) (B). M-H, Mantel-Haenszel; CI, confidence interval; RFA, radiofrequency ablation.

came statistically insignificant when four individual studies were removed, including most of the studies that compared EA with simple aspiration and saline instillation. The Egger test in- dicated no significant publication bias regarding the overall $\operatorname{SMD}(P=0.259)$. The funnel plot for the SMD of VRR is demonstrated in Fig. 5. 


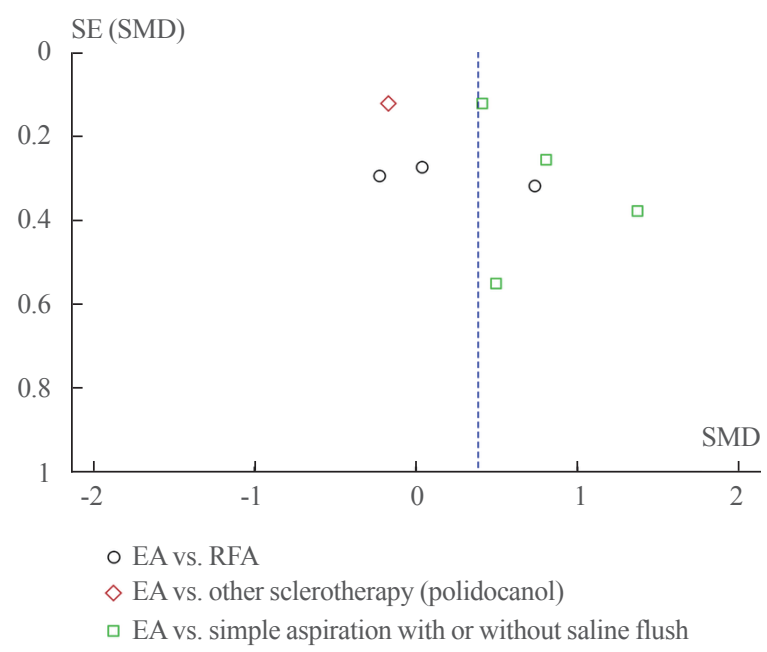

Fig. 5. Funnel plots of studies that evaluated the volume reduction ratio. SE, standard error; SMD, standardized mean difference; EA, ethanol ablation; RFA, radiofrequency ablation.

\section{DISCUSSION}

The present meta-analysis compared EA with other non-surgical types of management for the treatment of benign cystic thyroid nodules. Our results indicate that EA and RFA had comparable efficacy in treating cystic thyroid nodules with respect to VRR and the therapeutic success rate. This outcome is consistent with previous reports of high VRRs of RFA in both thyroid cysts and PCTNs (92.2\%-93.3\% and 83.7\%-87.5\%, respectively) [8,10, $13,44]$. However, RFA is more expensive than EA and requires more treatment sessions to have an effect $(1.67 \pm 0.86$ vs. $1.19 \pm$ $0.4, P=0.03)$. It is also associated with a greater tendency for the patient to experience pain, both during and after the procedure $[8,13]$. In addition, EA appeared more effective in reducing the volume of thyroid cysts, but not PCTNs, albeit not to a statistically significant degree. These results correspond with the observation of a greater VRR in cysts than in PCTNs after EA from a previous study $(89.7 \%$ vs. $78.2 \%, P<0.001)$ [45]. This can be explained by the conclusion of Kim et al. [12], who suggested that solid components of thyroid nodules are more refractory to EA based on their comparison of EA performed in cystic versus solid nodules. However, only one of the included studies compared EA with another form of sclerotherapy [9]. In fact, a variety of sclerosants in addition to ethanol have been adopted for the treatment of thyroid nodules, including tetracycline, sodium tetradecyl sulfate, N-butyl cyanoacrylate, and polidocanol [46-49]. Among them, polidocanol and sodium tetradecyl sulfate were compared with EA and were shown to have similar VRRs, but higher costs [9,47].

Several factors are known to compromise the efficacy of EA, particularly for PCTNs, including a relatively large initial nodule volume $(>20 \mathrm{~mL})$, increased vascularity, a solid portion $>20 \%$ of the total nodule, and a relatively low degree of cystic fluid aspiration prior to ethanol instillation $[35,45,50,51]$. Technical factors have also been explored. Kim et al. [52] and Park et al. [42] compared retention and aspiration methods of the injected ethanol and found no significant difference between the two methods in terms of the therapeutic success rate and VRR, respectively. Similarly, different durations of temporary ethanol retention (i.e., 2, 5, and 10 minutes) did not significantly affect the VRR in a study assessing the treatment of cysts and PCTNs [45]. However, our subgroup analysis showed that only studies that performed the retention technique, rather than the aspiration technique, had significantly higher VRRs than other non-surgical options. Nonetheless, Kim et al. [12] demonstrated that a larger injected volume of ethanol was positively correlated with the VRR in thyroid cysts $(P<0.01)$, but not in solid nodules. However, our subgroup analysis showed that EA achieved a significantly higher VRR in the group receiving a lower volume of ethanol instillation ( $<50 \%$ of the initial nodule volume), but not in the group with a higher injection volume. This is because patients in the control arm of the former group received conservative treatment (simple aspiration and saline flush) only. Moreover, the efficacy of EA is also influenced by the number of treatment sessions. Negro et al. [37] reported that the VRRs in thyroid cysts after the first, second, and third EA sessions were $66 \%, 74.4 \%$, and $79.4 \%$, respectively. Our subgroup analysis also showed that only studies that performed more than one session of EA in some or all of the patients demonstrated a significantly higher pooled VRR than the control management. Although the cure rate varied substantially across studies due to different definitions and numbers of interventions, Bennedbaek and Hegedus [11] reported a $64 \%$ cure rate (strictly defined as residual cyst volume $\leq 1 \mathrm{~mL}$ ) after a single session of EA in thyroid cysts. Furthermore, the long-term efficacy of EA for cystic thyroid nodules is satisfactory, although long-term results were reported in just a few studies. The VRRs at 2, 3, 5, and 10 years of follow-up in different studies were $72.7 \%-91.9 \%$, $73.2 \%-95.8 \%, 86.6 \%-98.5 \%$, and $70.2 \%-100 \%$, respectively $[7,34,38,53,54]$. The reported recurrence rates in thyroid cysts after EA were low $(3.1 \%-18 \%)$, and also varied according to the criteria that were used $[11,32,55]$. However, in a more recent study of PCTNs, the 1-month recurrence rate was $18.7 \%$, whereas delayed recurrence (mean, $10.1 \pm 8.5$ months) occurred 
in $24.1 \%$ of patients who initially did not show recurrence at 1 month of follow-up [51]. When faced with unsatisfactory results after EA, current guidelines [19,21] recommend performing subsequent RFA based on previous studies reporting that significant reductions in nodule volume and improvements in symptomatic and cosmetic problems were achieved after this combination therapy $[35,56]$. Similarly, for incomplete ablation of solid nodules adjacent to critical structures after RFA, introducing EA as an adjunct technique was shown to be an effective way to eliminate the residual solid component $[57,58]$.

EA is a safe procedure that is well-tolerated by most patients with benign thyroid cysts and PCTNs, with overall side effects that are mild and a considerably low incidence of major complications (self-limiting dysphonia, $0.53 \%$ ). In contrast, dysphonia was reported in 15 of 1,459 patients $(1.0 \%)$ who underwent RFA for benign thyroid nodules of unspecified morphological types in a large Korean multicenter study [59]. To our knowledge, permanent dysphonia after EA as a result of recurrent laryngeal nerve injury has never been reported, although severe necrosis of the skin and larynx without irreversible dysphonia was reported in one case involving treatment of a solid nodule [60]. Unlike with thermal ablation, the ablative effect of ethanol is limited to the nodule; therefore, EA does not disrupt thyroid function $[6,32,39]$. Moreover, local anesthesia was not required in most EA procedures. Notwithstanding its good safety profile, concerns can arise during the follow-up of patients treated with EA, as more than half of the remnant sclerosed nodules may mimic malignancy on ultrasound (i.e., marked hypoechogenicity), leading to unnecessary biopsies $[61,62]$.

The present meta-analysis has some limitations. First, although several studies have assessed EA for the treatment of thyroid diseases, only a few trials have compared EA with other therapies. This fact limited the size of the current meta-analysis. Second, substantial heterogeneity was found with respect to the pooled VRR and therapeutic success rate of EA versus other non-surgical managements. We performed sensitivity analyses, and the pooled VRRs did not reach statistical significance if most studies involving conservative treatment as a comparator were omitted. Therefore, the results of this investigation should be interpreted with caution. More high-quality RCTs comparing EA with other minimally invasive procedures are needed. Third, changes in symptomatic and cosmetic parameters could not be pooled due to a lack of standardized effect size. However, they were shown to parallel the VRR in four included studies [810,13] performed using the same scales. Lastly, novel thermal ablative techniques using technologies such as microwave, la- ser, and high-intensity focused ultrasound have been implemented in recent years to treat thyroid disease. Future research should compare EA with these new treatment options.

In conclusion, EA achieved a higher pooled VRR than other types of non-surgical management and appears to be more effective in the treatment of thyroid cysts than PCTNs. Although RFA has a comparable level of effectiveness to EA, it is associated with higher expenses and greater technical complexity. Our results reinforce the role of EA as the first-line treatment for symptomatic thyroid cysts and PCTNs, given its high effectiveness, low-cost, and good safety profile.

\section{CONFLICTS OF INTEREST}

No potential conflict of interest relevant to this article was reported.

\section{ACKNOWLEDGMENTS}

We are grateful to Dr. Chung-Han Ho for his help with the statistical analysis.

\section{AUTHOR CONTRIBUTIONS}

Conception or design: C.C.Y., Y.H., J.Y.L. Acquisition, analysis, or interpretation of data: C.C.Y., Y.H. Drafting the work or revising: C.C.Y., Y.H., J.Y.L. Final approval of the manuscript: C.C.Y., Y.H., J.Y.L.

\section{ORCID}

Cheng-Chun Yang https://orcid.org/0000-0002-1124-8154

Jyun-Yan Liou https://orcid.org/0000-0002-0044-853X

\section{REFERENCES}

1. Russ G, Leboulleux S, Leenhardt L, Hegedus L. Thyroid incidentalomas: epidemiology, risk stratification with ultrasound and workup. Eur Thyroid J 2014;3:154-63.

2. Rojeski MT, Gharib H. Nodular thyroid disease. Evaluation and management. N Engl J Med 1985;313:428-36.

3. Durante C, Grani G, Lamartina L, Filetti S, Mandel SJ, Cooper DS. The diagnosis and management of thyroid nodules: a review. JAMA 2018;319:914-24.

4. Smith MD, Serpell JW, Morgan JL, Cheng MS. Fine needle aspiration in the management of benign thyroid cysts. ANZ 
J Surg 2003;73:477-9.

5. Choi WJ, Baek JH, Choi YJ, Lee JH, Ha EJ, Lee WC, et al. Management of cystic or predominantly cystic thyroid nodules: role of simple aspiration of internal fluid. Endocr Res 2015;40:215-9.

6. Ferreira MC, Piaia C, Cadore AC. Percutaneous ethanol injection versus conservative treatment for benign cystic and mixed thyroid nodules. Arch Endocrinol Metab 2016;60:211-6.

7. Zingrillo M, Torlontano M, Chiarella R, Ghiggi MR, Nirchio V, Bisceglia M, et al. Percutaneous ethanol injection may be a definitive treatment for symptomatic thyroid cystic nodules not treatable by surgery: five-year follow-up study. Thyroid 1999;9:763-7.

8. Sung JY, Kim YS, Choi H, Lee JH, Baek JH. Optimum firstline treatment technique for benign cystic thyroid nodules: ethanol ablation or radiofrequency ablation? AJR Am J Roentgenol 2011;196:W210-4.

9. Gong X, Wang F, Du H, Chen X, Shi B. Comparison of ultrasound-guided percutaneous polidocanol injection versus percutaneous ethanol injection for treatment of benign cystic thyroid nodules. J Ultrasound Med 2018;37:1423-9.

10. Sung JY, Baek JH, Kim KS, Lee D, Yoo H, Kim JK, et al. Single-session treatment of benign cystic thyroid nodules with ethanol versus radiofrequency ablation: a prospective randomized study. Radiology 2013;269:293-300.

11. Bennedbaek FN, Hegedus L. Treatment of recurrent thyroid cysts with ethanol: a randomized double-blind controlled trial. J Clin Endocrinol Metab 2003;88:5773-7.

12. Kim JH, Lee HK, Lee JH, Ahn IM, Choi CG. Efficacy of sonographically guided percutaneous ethanol injection for treatment of thyroid cysts versus solid thyroid nodules. AJR Am J Roentgenol 2003;180:1723-6.

13. Baek JH, Ha EJ, Choi YJ, Sung JY, Kim JK, Shong YK. Radiofrequency versus ethanol ablation for treating predominantly cystic thyroid nodules: a randomized clinical trial. Korean J Radiol 2015;16:1332-40.

14. Gharib H, Papini E, Garber JR, Duick DS, Harrell RM, Hegedus L, et al. American Association of Clinical Endocrinologists, American College of Endocrinology, and Associazione Medici Endocrinologi medical guidelines for clinical practice for the diagnosis and management of thyroid nodules: 2016 update. Endocr Pract 2016;22:622-39.

15. Shiina S, Tagawa K, Unuma T, Takanashi R, Yoshiura K, Komatsu Y, et al. Percutaneous ethanol injection therapy for hepatocellular carcinoma. A histopathologic study. Cancer 1991;68:1524-30.
16. Albanese G, Kondo KL. Pharmacology of sclerotherapy. Semin Intervent Radiol 2010;27:391-9.

17. Ahmed M, Brace CL, Lee FT Jr, Goldberg SN. Principles of and advances in percutaneous ablation. Radiology 2011; 258:351-69.

18. Haugen BR, Alexander EK, Bible KC, Doherty GM, Mandel SJ, Nikiforov YE, et al. 2015 American Thyroid Association management guidelines for adult patients with thyroid nodules and differentiated thyroid cancer: the American Thyroid Association Guidelines Task Force on thyroid nodules and differentiated thyroid cancer. Thyroid 2016;26:1133.

19. Papini E, Monpeyssen H, Frasoldati A, Hegedus L. 2020 European Thyroid Association clinical practice guideline for the use of image-guided ablation in benign thyroid nodules. Eur Thyroid J 2020;9:172-85.

20. Feldkamp J, Grunwald F, Luster M, Lorenz K, Vorlander C, Fuhrer D. Non-surgical and non-radioiodine techniques for ablation of benign thyroid nodules: consensus statement and recommendation. Exp Clin Endocrinol Diabetes 2020; 128:687-92.

21. Kim JH, Baek JH, Lim HK, Ahn HS, Baek SM, Choi YJ, et al. 2017 Thyroid radiofrequency ablation guideline: Korean Society of Thyroid Radiology. Korean J Radiol 2018;19:63255.

22. Hahn SY, Shin JH, Na DG, Ha EJ, Ahn HS, Lim HK, et al. Ethanol ablation of the thyroid nodules: 2018 consensus statement by the Korean Society of Thyroid Radiology. Korean J Radiol 2019;20:609-20.

23. Jeong WK, Baek JH, Rhim H, Kim YS, Kwak MS, Jeong $\mathrm{HJ}$, et al. Radiofrequency ablation of benign thyroid nodules: safety and imaging follow-up in 236 patients. Eur Radiol 2008; 18:1244-50.

24. Lim HK, Lee JH, Ha EJ, Sung JY, Kim JK, Baek JH. Radiofrequency ablation of benign non-functioning thyroid nodules: 4-year follow-up results for 111 patients. Eur Radiol 2013;23:1044-9.

25. Aysan E, Idiz UO, Akbulut H, Elmas L. Single-session radiofrequency ablation on benign thyroid nodules: a prospective single center study : radiofrequency ablation on thyroid. Langenbecks Arch Surg 2016;401:357-63.

26. Kim YS, Rhim H, Tae K, Park DW, Kim ST. Radiofrequency ablation of benign cold thyroid nodules: initial clinical experience. Thyroid 2006;16:361-7.

27. Khalilzadeh O, Baerlocher MO, Shyn PB, Connolly BL, Devane AM, Morris CS, et al. Proposal of a new adverse 
event classification by the Society of Interventional Radiology Standards of Practice Committee. J Vasc Interv Radiol 2017;28:1432-7.

28. Sterne JAC, Savovic J, Page MJ, Elbers RG, Blencowe NS, Boutron I, et al. RoB 2: a revised tool for assessing risk of bias in randomised trials. BMJ 2019;366:14898.

29. Kim SY, Park JE, Lee YJ, Seo HJ, Sheen SS, Hahn S, et al. Testing a tool for assessing the risk of bias for nonrandomized studies showed moderate reliability and promising validity. J Clin Epidemiol 2013;66:408-14.

30. Higgins JP, Thompson SG, Deeks JJ, Altman DG. Measuring inconsistency in meta-analyses. BMJ 2003;327:557-60.

31. Valcavi R, Frasoldati A. Ultrasound-guided percutaneous ethanol injection therapy in thyroid cystic nodules. Endocr Pract 2004;10:269-75.

32. Verde G, Papini E, Pacella CM, Gallotti C, Delpiano S, Strada $\mathrm{S}$, et al. Ultrasound guided percutaneous ethanol injection in the treatment of cystic thyroid nodules. Clin Endocrinol (Oxf) 1994;41:719-24.

33. Cho YS, Lee HK, Ahn IM, Lim SM, Kim DH, Choi CG, et al. Sonographically guided ethanol sclerotherapy for benign thyroid cysts: results in 22 patients. AJR Am J Roentgenol 2000;174:213-6.

34. Guglielmi R, Pacella CM, Bianchini A, Bizzarri G, Rinaldi R, Graziano FM, et al. Percutaneous ethanol injection treatment in benign thyroid lesions: role and efficacy. Thyroid 2004;14:125-31.

35. Jang SW, Baek JH, Kim JK, Sung JY, Choi H, Lim HK, et al. How to manage the patients with unsatisfactory results after ethanol ablation for thyroid nodules: role of radiofrequency ablation. Eur J Radiol 2012;81:905-10.

36. Perez CL, Fighera TM, Miasaki F, Mesa Junior CO, Paz Filho GJ, Graf H, et al. Evaluation of percutaneous ethanol injections in benign thyroid nodules. Arq Bras Endocrinol Metabol 2014;58:912-7.

37. Negro R, Colosimo E, Greco G. Outcome, pain perception, and health-related quality of life in patients submitted to percutaneous ethanol injection for simple thyroid cysts. J Thyroid Res 2017;2017:9536479.

38. Espenbetova M, Amrenova K, Zhumanbayeva Z, Zamanbekova Z, Yurkovskaya O, Shalgumbayeva G, et al. Effectiveness of percutaneous ethanol injection in nodular diseases of the thyroid gland: 10-year follow-up. Endoc Pract 2018;24:982-7.

39. Ozderya A, Aydin K, Gokkaya N, Temizkan S. Percutaneous ethanol injection for benign cystic and mixed thyroid nodules. Endocr Pract 2018;24:548-55.

40. Halenka M, Karasek D, Schovanek J, Frysak Z. Safe and effective percutaneous ethanol injection therapy of 200 thyroid cysts. Biomed Pap Med Fac Univ Palacky Olomouc Czech Repub 2020;164:161-7.

41. Reverter JL, Alonso N, Avila M, Lucas A, Mauricio D, PuigDomingo M. Evaluation of efficacy, safety, pain perception and health-related quality of life of percutaneous ethanol injection as first-line treatment in symptomatic thyroid cysts. BMC Endocr Disord 2015;15:73.

42. Park HS, Yim Y, Baek JH, Choi YJ, Shong YK, Lee JH. Ethanol ablation as a treatment strategy for benign cystic thyroid nodules: a comparison of the ethanol retention and aspiration techniques. Ultrasonography 2019;38:166-71.

43. Friedrich JO, Adhikari NK, Beyene J. Inclusion of zero total event trials in meta-analyses maintains analytic consistency and incorporates all available data. BMC Med Res Methodol 2007;7:5.

44. Lee GM, You JY, Kim HY, Chai YJ, Kim HK, Dionigi G, et al. Successful radiofrequency ablation strategies for benign thyroid nodules. Endocrine 2019;64:316-21.

45. Kim YJ, Baek JH, Ha EJ, Lim HK, Lee JH, Sung JY, et al. Cystic versus predominantly cystic thyroid nodules: efficacy of ethanol ablation and analysis of related factors. Eur Radiol 2012;22:1573-8.

46. Hegedus L, Hansen JM, Karstrup S, Torp-Pedersen S, Juul N. Tetracycline for sclerosis of thyroid cysts. A randomized study. Arch Intern Med 1988;148:1116-8.

47. Kalra N, Ahuja CK, Dutta P, Rajwanshi A, Mittal BR, Bhansali A, et al. Comparison of sonographically guided percutaneous sodium tetradecyl sulfate injection with ethanol injection in the treatment of benign nonfunctioning thyroid nodules. J Vasc Interv Radiol 2014;25:1218-24.

48. Dong Y, Zhou J, Liu Z, Luo T, Zhan W. Efficacy assessment of ultrasound guided lauromacrogol injection for ablation of benign cystic and predominantly cystic thyroid nodules. Front Pharmacol 2019;10:478.

49. Yuce G, Ates OF, Polat B, Genc B, Canyigit M. Ablation of cystic thyroid nodules with n-butyl cyanoacrylate: a preliminary study. Endocr Pract 2020;26:492-8.

50. In HS, Kim DW, Choo HJ, Jung SJ, Kang T, Ryu JH. Ethanol ablation of benign thyroid cysts and predominantly cystic thyroid nodules: factors that predict outcome. Endocrine 2014;46:107-13.

51. Suh CH, Baek JH, Ha EJ, Choi YJ, Lee JH, Kim JK, et al. Ethanol ablation of predominantly cystic thyroid nodules: 
evaluation of recurrence rate and factors related to recurrence. Clin Radiol 2015;70:42-7.

52. Kim DW, Rho MH, Kim HJ, Kwon JS, Sung YS, Lee SW. Percutaneous ethanol injection for benign cystic thyroid nodules: is aspiration of ethanol-mixed fluid advantageous? AJNR Am J Neuroradiol 2005;26:2122-7.

53. Lee SJ, Ahn IM. Effectiveness of percutaneous ethanol injection therapy in benign nodular and cystic thyroid diseases: long-term follow-up experience. Endocr J 2005;52:455-62.

54. Solymosi T. Percutaneous ethanol injection efficacy in the treatment of benign thyroid nodules. Ten-year follow-up of 254 patients. Orv Hetil 2020;161:224-31.

55. Monzani F, Lippi F, Goletti O, Del Guerra P, Caraccio N, Lippolis PV, et al. Percutaneous aspiration and ethanol sclerotherapy for thyroid cysts. J Clin Endocrinol Metab 1994;78:800-2.

56. Lee JH, Kim YS, Lee D, Choi H, Yoo H, Baek JH. Radiofrequency ablation (RFA) of benign thyroid nodules in patients with incompletely resolved clinical problems after ethanol ablation (EA). World J Surg 2010;34:1488-93.

57. Kim DW. Sonography-guided ethanol ablation of a remnant solid component after radio-frequency ablation of benign solid thyroid nodules: a preliminary study. AJNR Am J Neu- roradiol 2012;33:1139-43.

58. Park HS, Baek JH, Choi YJ, Lee JH. Innovative techniques for image-guided ablation of benign thyroid nodules: combined ethanol and radiofrequency ablation. Korean J Radiol 2017;18:461-9.

59. Baek JH, Lee JH, Sung JY, Bae JI, Kim KT, Sim J, et al. Complications encountered in the treatment of benign thyroid nodules with US-guided radiofrequency ablation: a multicenter study. Radiology 2012;262:335-42.

60. Mauz PS, Maassen MM, Braun B, Brosch S. How safe is percutaneous ethanol injection for treatment of thyroid nodule? Report of a case of severe toxic necrosis of the larynx and adjacent skin. Acta Otolaryngol 2004;124:1226-30.

61. Park NH, Kim DW, Park HJ, Lee EJ, Park JS, Park SI, et al. Thyroid cysts treated with ethanol ablation can mimic malignancy during sonographic follow-up. J Clin Ultrasound 2011;39:441-6.

62. Park JS, Kim DW, Eun CK, Choi SJ, Rho MH. Long-term follow-up sonography of benign cystic thyroid nodules after a percutaneous ethanol injection: the incidence of malignancy-mimicking nodules. J Korean Radiol Soc 2008;58:21-8. 